\title{
A DATA CAPTURE FRAMEWORK FOR IMPROVING THE QUALITY OF SUBSURFACE UTILITY INFORMATION
}

\author{
R. van Son ${ }^{1}$, Jaw S.W. ${ }^{1,2,3}$, A. Wieser ${ }^{4}$ \\ ${ }^{1}$ Singapore-ETH Centre, ETH Zürich, Singapore - (vanson, jaw)@arch.ethz.ch \\ ${ }^{2}$ Geoscience \& Digital Earth Centre (INSTeG), Research Institute for Sustainable Environment, Universiti Teknologi Malaysia, \\ Malaysia-swjaw@utm.my \\ ${ }^{3}$ Department of Geoinformation, Faculty of Geoinformation \& Real Estate, Universiti Teknologi Malaysia, Malaysia \\ ${ }^{4}$ Institute of Geodesy and Photogrammetry, ETH Zürich, Switzerland - andreas.wieser@geod.baug.ethz.ch
}

Commission VI, WG VI/10

KEY WORDS: Underground Utility Mapping, 3D Mapping, Digital Twin

\begin{abstract}
:
To plan, develop, and manage underground space and make informed decisions leading to desirable outcomes, planners, land administrators, and engineers need to make sense of the underground. A reliable digital twin of the underground - a realistic, digital representation of the physical world below the surface - is required. Utilities, consisting of the pipes, ducts, cables, manholes and other assets that provide electricity, gas, water, sewerage, and telecommunication services, make up a significant portion of the shallow layers of the subsurface. A lack of reliable information on subsurface utilities may potentially lead to poor decisions leading to undesirable outcomes, lengthy and costly planning and land administration processes, and lengthy, costly, and hazardous development processes. The advent of mobile 3D ground penetrating radar technology offers the promise of non-destructive mapping of existing subsurface utilities in a large area in a relatively short amount of time and could potentially be used to improve the reliability of available information. In this work, a small number of cases studies are described at evaluating the feasibility of a large area mapping approach for subsurface utilities. Based on the results of the studies, a data capture framework for the gradual improvement of the quality of information on existing subsurface utilities is proposed.
\end{abstract}

\section{INTRODUCTION}

In March 2019, the Urban Redevelopment Authority of Singapore unveiled its Draft Master Plan 2019 to guide Singapore's development for the next 10 to 15 years (Urban Redevelopment Authority, 2019). The use of underground space is one of its strategies to create space for the land-scarce citystate's growing needs. A large number of underground developments are already in place, in progress, or in place. As a consequence, Singapore's underground space is becoming more and more congested, and the development and use of underground space is becoming an increasingly challenging task. A reliable digital representation of the underground is required to enable professionals to make informed decisions.

The Digital Underground project addresses the lack of a reliable map of subsurface utilities for planning and land administration in Singapore and aims to develop a roadmap towards more accurate, current, and complete information. Recent industry developments towards the use of ground penetrating radar technology for subsurface utility mapping offer a compelling and promising case for government agencies and utility owners. In this work, we describe the activities conducted by the project to assess the feasibility of mobile 3D ground penetrating radar technology to map subsurface utilities for large areas in a single, concerted effort.

In October 2018, a number of case studies were conducted, collecting data in 9 areas in Singapore. These data were processed to detect and locate subsurface utilities. The results were compared to available map data on existing subsurface utilities. Also, the practical operation of the platform was evaluated. From these results, it can be concluded that, while raw data capture can be considered fast, the processing of that data is still a laborious effort that will likely result in valuable information.

The results of the case studies serve as key discussion points on the feasibility of large area subsurface utility mapping projects possibly to be scaled up to a nation-wide mapping approach, similar to national mapping projects already in place for above the surface. Based on this, a data capture framework for the reconciliation of the quality of information on existing subsurface utilities is proposed that operates on the principle of a piecemeal, gradual improvement of information quality instead of a single, nation-wide effort. It is recommended that such a framework capitalizes on opportunities where a clear and proven business case for a non-destructive mapping approach exists. Additionally, it is recommended that the limited opportunities that provide an unobstructed line of sight and accessibility to subsurface utilities are used to capture data using conventional and alternative surveying techniques.

\section{THE NEED FOR A RELIABLE MAP OF SUBSURFACE UTILITIES}

To plan, develop, and manage underground space and make informed decisions leading to desirable outcomes, planners, land administrators, and engineers need to make sense of the underground. A reliable digital twin of the underground - a realistic, digital representation of the physical world below the surface - is required. Utilities, consisting of the pipes, ducts, cables, manholes and other assets that provide electricity, gas, water, sewerage, and telecommunication services, make up a significant portion of the shallow layers of the subsurface. 
Having unreliable information of underground utilities may potentially result in (i) not well-informed planning decisions upfront, resulting in lengthy planning and development processes, risky configurations of underground assets, and a loss of opportunity for future uses of space, (ii) inefficient and costly land administration processes all throughout the life cycle of the land, and (iii) additional utility locating costs, delays, safety hazards, and loss of services due to utility strikes during excavation works.

\subsection{Urban planning}

Urban planners working for land development agencies in Singapore need reliable information on subsurface utilities for the planning and safeguarding of underground space for future use. Utility information is required to ensure the following outcomes: (i) to plan for the future use of underground space, (ii) to safeguard underground space for future use during development and approval of plans for underground development incl. utilities, and (iii) to ensure minimum clearance from existing underground assets during development and approval of plans for underground development incl. utilities.

The best-case scenario for planners is to plan for underground space upfront. To do so, in particular with an already congested underground space, reliable information on subsurface utilities is of the essence. Conversely, the lack of a reliable map can have far-reaching effects. Poor as-built records of subsurface utilities can lead to a planned utility layout not being available, typically resulting in the nearest available (non-planned) path being used, which may not be recorded accurately. As such, unreliable information leads to additional cost and duration for utility installation. Even more so, it can lead to unpredictable and unknown layouts that can negatively impact any future utility installation or other underground developments, limiting the ability for future services to be constructed and impeding construction of other infrastructure underground.

As such, the lack of a reliable map can potentially lead to (i) planning being more complicated, lengthy, and costly than necessary, (ii) utility installation being more lengthy and costly than anticipated, (iii) situations that can potentially affect the safety and resilience of existing underground infrastructure, and (iv) the loss of opportunity for future underground space use.

\subsection{Land administration}

In Singapore, a large portion of land is owned by the state. State land is actively managed by the various land development agencies of Singapore. The administration of state land comprises a range of processes to administer, including land ownership and conflict management, taxation, land acquisition, land lease, land use planning, land development, and land sales.

\begin{tabular}{|c|c|}
\hline Life cycle phase & Value of reliable information \\
\hline Land acquisition & \\
\hline and purchase & encumbrances below the surface. \\
\hline Land rejuvenation & $\begin{array}{l}\text { Assessment and location of subsurface } \\
\text { encumbrances to be removed. }\end{array}$ \\
\hline Planning and & Development and evaluation of plans \\
\hline coordination & for underground development. \\
\hline Interim land use & Facilitation of interim land use plans. \\
\hline $\begin{array}{l}\text { Land transfer and } \\
\text { sales }\end{array}$ & $\begin{array}{l}\text { Provision of correct and complete } \\
\text { information on land for sale. }\end{array}$ \\
\hline
\end{tabular}

Table 1. Value of reliable information for land administration purposes
In a workshop conducted in October 2018, representatives from various land administration departments within Singapore Land Authority shared their perspective on the value of a reliable map. The results are summarized in Table 1.

\subsection{Underground construction and excavation works}

Any construction project that involves excavation requires efforts to locate existing utilities prior to construction. The availability of reliable information can lead to various cost reductions. This value is well known and documented for cases in Ontario and the United States (Osman \& El-Diraby, 2005, and Zembillas \& Scott, 2010). In this section, a few examples are highlighted to underline the importance of reliable subsurface utility information for underground construction works.

2.3.1 Utility locating prior to excavation: The value of reliable information for the purpose of locating existing utilities prior to excavation can be supported by a few notable examples. For the Sydney Light Rail Extension Project, significant work was performed to collect available map data of existing underground utilities prior to awarding the contract for construction. The available information often turned out to be unreliable and, additionally, many more unknown utility services were encountered during construction. Eventually, it was estimated that the availability of reliable and complete information would have resulted in project completion one and a half years earlier, a severe cost reduction, and lower risk for construction workers involved (Zeiss, 2019).

In the United States, construction projects are understood to inflate bids by an estimated $10-30 \%$ in order to accommodate risk associated with unknown or poorly mapped utilities. Conversely, an estimated USD 10M was saved during the I-20/I-59 Corridor project in Alabama by capturing and sharing information in advance to all contractors involved. Existing records were combined with ground penetrating radar scans, electromagnetic locator readings and trial trenches to develop a reliable, 3D map (Zeiss, 2019).

2.3.2 The cost of utility strikes during excavation: A lack of reliable information on subsurface utilities increases the risk of utility strikes during underground construction and excavation work. Utility strikes can result in damage to the pipe or cable that was hit. Even more so, it has indirect and social costs, including traffic disruption, injuries, and loss of business. Makana et al. (2016) estimate the indirect and social cost to be 29 times the direct cost of the utility strike for cases studied in the United Kingdom.

In the Netherlands, around 33,000 utility strikes were reported in 2017. The total associated cost was estimated to be EUR 25.2M (Agentschap Telecom, 2018).

In Singapore, the number of reported utility strikes is unknown. In (Tham, 2019) it is mentioned that "Singapore has suffered 26 cases of telecommunication cable cuts in the past three years that resulted in hours or days of Internet and telephony service outages". The Energy Market Authority mentions "a fine not exceeding \$1 million or imprisonment for a term not exceeding five years, or both" as the penalty for earthworks contractors accompanied by a list of over 40 convicted earthworks contractors since 2013 (Energy Market Authority, 2019). 


\subsection{Reliability as the product of quality}

A digital twin, map, or spatial dataset is reliable when it can be trusted and depended on consistently for a specific application or task. The described work operates on the premise that a sufficient degree of quality of subsurface utility information is required for planning, land administration, and underground development work applications. Based on workshops and interviews conducted with potential end users, the following aspects were identified as most significant with respect to information quality:

Spatial accuracy, i.e. the degree of closeness to which geographical positions and dimensions match the real world Currency, i.e. the degree to which data is up to date and reflects the current state of the real world.

Completeness, i.e. the degree of absence of gaps between spatial objects that are represented in the available data and what really exists in the real world.

An analysis of available data and experiences from its users leads to the conclusion that the current degree of quality is generally considered insufficient. Available subsurface utility information is often inaccurate or of unknown accuracy. Reasons for this include the use of a cartography-centric approach to data (re)presentation, a lack of (accurate) surveying in the past, no efforts to improve the quality of information, and the lack of depth or elevation information.

\subsection{Digital Underground: Towards a reliable map}

The Digital Underground project is an initiative of the Singapore Land Authority and the Singapore-ETH Centre. The main objective of the project is to develop a roadmap, outlining the actions and milestones that ultimately lead to the establishment and sustenance of a reliable map of subsurface utilities in Singapore.

Among other subjects, Digital Underground's research activities focus on the question how non-destructive surveying and mapping techniques - in particular ground penetrating radar - can be used to improve the quality of subsurface utility information in Singapore.

\section{TECHNIQUES FOR SURVEYING AND MAPPING SUBSURFACE UTILITIES}

In (Van Son et al., 2018) a comprehensive overview of techniques for surveying and mapping of subsurface utilities is described that includes conventional surveying techniques, point cloud-based techniques, geophysical techniques, and gyroscopic mapping.

In Singapore, from 2017 onwards, utility laying contractors have been mandated to provide accurate, $3 \mathrm{D}$ as-built records of all newly built utilities according to the Standard and Specifications for Utility Survey in Singapore (Singapore Land Authority, 2017). The standard currently endorses the use of total station, GNSS Real Time Kinematic, and 3D laser scanning as suitable techniques for surveying utilities. In practice, conventional surveying techniques are used almost exclusively and laser scanning is currently not extensively adopted by utility surveyors in Singapore.

All of the endorsed techniques require an unobstructed line of sight and access to the newly built asset as well as sufficient time to conduct a proper survey before backfilling of the soil occurs.
However, these opportunities are not always available and the lack of accuracy of information on existing, buried subsurface utilities remains to be reconciled. Exposing existing buried utilities and re-surveying them in order to improve quality is not feasible as it would be complicated, costly, and often leading to significant disruptions to road traffic. Other opportunities, such as digging trial trenches prior to excavation or pipeline repairs are sparse, spatially limited, and offer a very short time window.

\subsection{The use of ground penetrating radar for mapping buried subsurface utilities}

In recent years, techniques for subsurface utility mapping that no longer require an underground asset to be exposed, such as ground penetrating radar, have become commercially available at a large scale.

Ground penetrating radar (GPR) is one of the most commonly used technologies for the detection and mapping of utilities buried underground (Lai et al., 2018). The GPR antenna transmits electromagnetic signals into the ground and records the signals that are reflected on the ground surface when it encounters buried objects. Off the shelf ground penetrating radar systems are typically incorporated into a small trolley that can be pushed over the target area.

So-called multichannel 3D GPR array systems (Novo et al., 2013) have become commercially available in recent years. These array systems consist of a large number of closely-spaced antennas, enabling them to produce high-resolution 3D radargrams in a relatively small amount of time. These systems can be mounted on or towed by regular road-based vehicles. This offers the potential of capturing large volumes of data in a relatively small amount of time, while at the same time minimizing traffic disruptions.

Underlining the growing need, use, and acceptance of ground penetrating radar as a utility mapping technique, a small but growing number of countries and cities have introduced standards that aim to formalize and standardize practices of and surrounding mapping newly built and existing buried subsurface utilities. These standards incorporate and endorse the use of ground penetrating radar, often along with the use of electromagnetic location techniques. These include the United States, Canada, the United Kingdom, Malaysia, Australia, and Hong Kong.

\section{CASE STUDY APPROACH}

A case study was conducted to assess the feasibility and benefit of the use of $3 \mathrm{D}$ ground penetrating radar technology for subsurface utility mapping.

\subsection{Case study objectives}

The objectives of the case studies with 3D GPR were to (i) assess the practical feasibility of operating a 3D GPR mobile mapping platform on the streets of Singapore and (ii) assess the feasibility and viability of large volume, large area data subsurface capture to improve the quality of existing utilities.

\subsection{Data capture locations}

Nine study areas were selected in different areas of Singapore. The selection includes a "virgin" practice area (near the future Canberra MRT station), relatively new residential estates 
(Punggol and Sengkang), relatively old residential estates (Ang Mo Kio and Toa Payoh), parts of the central business district (Raffles Boulevard and Marina Boulevard), an industrial estate (Woodlands Spectrum), and the University Town campus of the National University of Singapore. With the selection of different areas, it was attempted to investigate different subsurface contexts, e.g. different soil conditions, different utility layouts, and changes due to the progression of the sub-surface over time.

\subsection{Technology used for data capture}

The Leica Pegasus:Stream mobile mapping platform was deployed at the selected study sites. The Pegasus: Stream combines a Stream EM GPR array with a Leica Pegasus Two photo and laser scanner. It is an integrated hardware solution for 3D mapping of the above ground and the underground. The large GPR array consisting of 40 antennae transmitting and receiving in two distinct polarisations allows for the collection of data for swaths of surface at a time. Simultaneously, the system can capture calibrated imagery and point clouds of above ground features. All the data captured by the Pegasus: Stream was georeferenced using a combination of on-board sensors that include a GNSS receiver, an Inertial Measurement Unit (IMU), and a Distance Measurement Instrument (DMI).

\subsection{Practical operation}

The platform was towed behind a vehicle moving at a speed of not exceeding $15 \mathrm{~km} / \mathrm{h}$. This means it can theoretically cover and capture data of over tens of hectares per day. The potential of large-area data capture without interruption of traffic flows can reduce cost and time for mapping significantly. Despite this and due to the slow speed of movement and lack of safety features on the platform itself, auxiliary police escorting services were hired. A special purpose license was acquired from the Land Transport Authority of Singapore to allow the platform on the roads of the selected case study areas only. To enable the capture of above ground data using the on-board laser scanner, data was captured in daylight conditions.

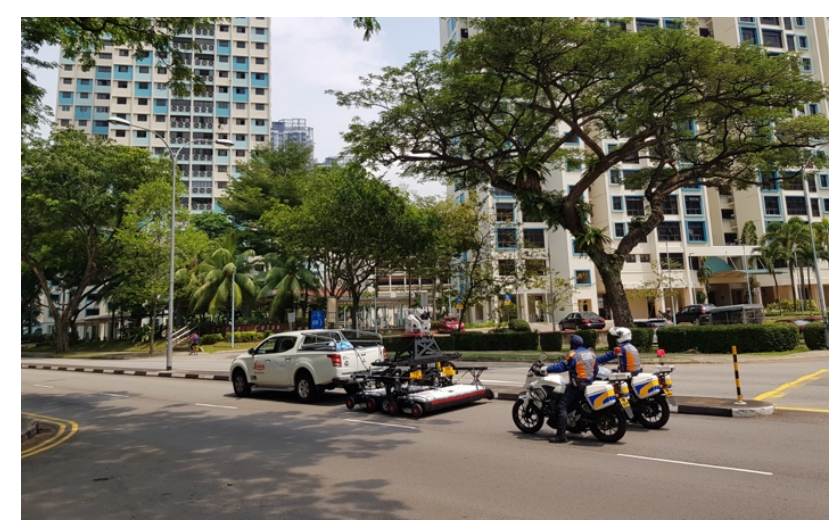

Figure 1. Data capture in Toa Payoh, Singapore.

For a single scan, the Stream EM can cover a swath of $1.75 \mathrm{~m}$ in width. In Singapore, road lane width is often $3.2 \mathrm{~m}$ or wider. Therefore, two scan tracks are typically required to cover a single lane and multiple passes of the same road were required to cover the entire surface of the road (Figure 2). The platform was only used on the surface of the road and not on the adjoining side table.

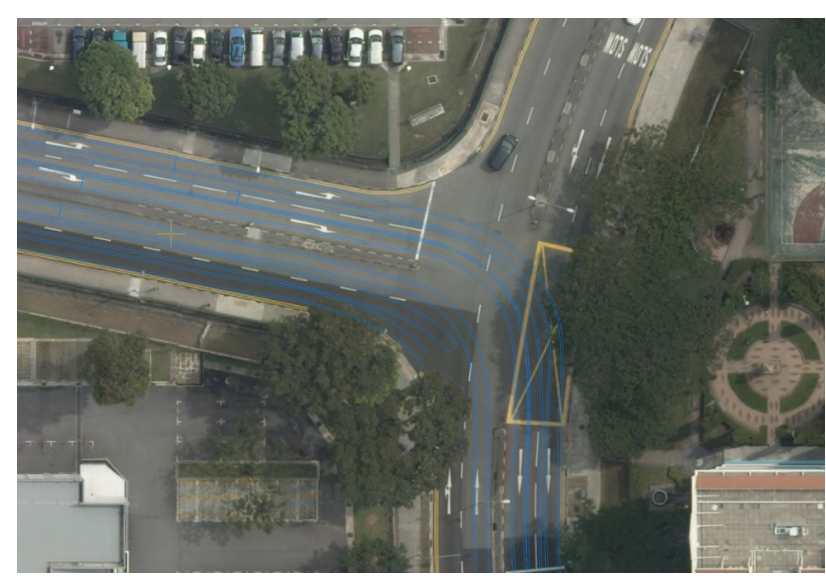

Figure 2. Blue lines indicate the outlines of multiple overlapping scan tracks for a single road.

\subsection{Data processing}

All acquired data were pre-processed to enhance the quality of the radargram before further interpretation. After that, postprocessing of the captured data was conducted in order to interpret the data and detect, locate, and extract subsurface utilities from the captured data. After that, the data was exported to $\mathrm{CAD}$ and GIS formats for further 3D modelling and visualization. For post-processing, the GRED HD 3D CAD software package was used. The post-processing was conducted by a specialized ground penetrating radar data analyst with over 5 years of GPR processing experience.

\subsection{Data comparison}

To assess the quality of data captured from each site, the captured data was compared to available 2D map data provided by various utility owners in Singapore through the GeoSpace platform. The comparison was conducted based on basic visual cues such as proximity, overlap, and geometric similarity of features. No further verification of the extracted results was conducted.

\section{RESULTS}

Due to an unanticipated amount of time required for postprocessing and comparison of the data, the captured data of only three areas were eventually post-processed and analysed for comparison with available map data. These areas were in (i) Toa Payoh and (ii) Ang Mo Kio, two relatively old residential estates in Singapore containing many developments from the 1960s and 1970s, and (iii) Marina Boulevard, a commercial district in Singapore's Central Business District area, built on recently reclaimed land featuring many developments in the 2010s.

\subsection{Toa Payoh}

The main scanning route in Toa Payoh was a bi-directional loop around the selected area. The total length for one loop is about $1.8 \mathrm{~km}$. All roads consist of 4 lanes (2 lanes for each carriageway).

The scanning at Toa Payoh proved to be challenging due to local traffic conditions and took a longer time to complete as compared to newer residential estates such as Punggol or Sengkang. The total time need for the scanning at Toa Payoh is 5-6 hours while the scanning at Punggol or Sengkang was about 3.5 hours. 
An excerpt near the northwest corner of the scanning area is highlighted in greater detail. Figures 3 and 4 display the available map data and the extracted utilities, respectively. As indicated by available map data, 4 utilities run parallel to the road direction. There are also 4 utilities detected by GPR for that same road. However, the alignment of the utilities detected is different from the available map data, except for those utilities that are at the left and right side of both carriageways. The alignment of the utilities extracted from the GPR data at the centre of the carriageway and on the left lane match the available data very well.

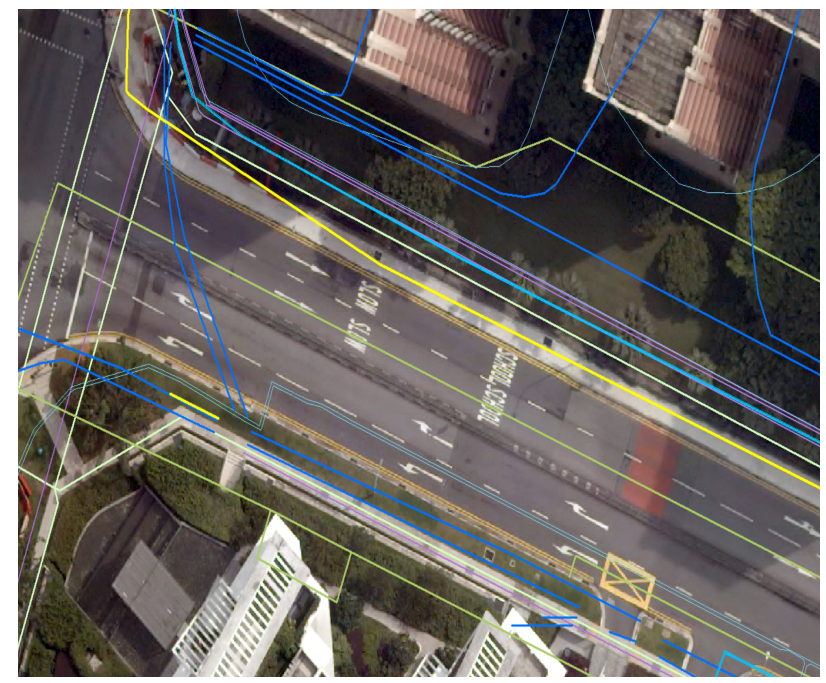

Figure 3. Available map data on existing utilities in highlighted area, Toa Payoh.

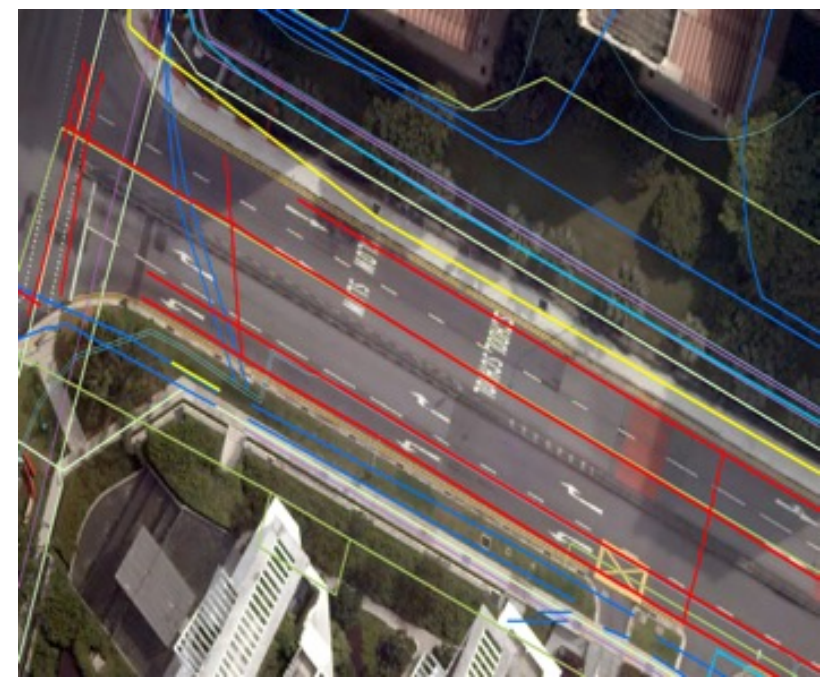

Figure 4. Extracted utilities (red lines) in highlighted area, Toa Payoh.

According to available map data, one utility and two drain lines and ducts cross the road. Five utilities were detected by the GPR. Only one utility on the left matches the available data. Other utilities are either not mapped accurately or not present in the available data. As the type and size of the utility assets can't be extracted from radar data alone unless further processing and additional data capture are performed, it is not possible to assess this difference in further detail. Further verification, such as trial pit measurements, are required to verify these detection results.

\subsection{Ang Mo Kio}

The main scanning route in Ang Mo Kio is a bi-directional loop around the selected area. The total length for one loop is about $1.75 \mathrm{~km}$. All roads consist of 4 lanes $(2$ lanes in each carriageway). 2 bus lanes run along the sides of one of the roads.

For detailed evaluation, an excerpt is assessed in greater detail. Figures 5 and 6 display the available map data and the extracted utilities, respectively.

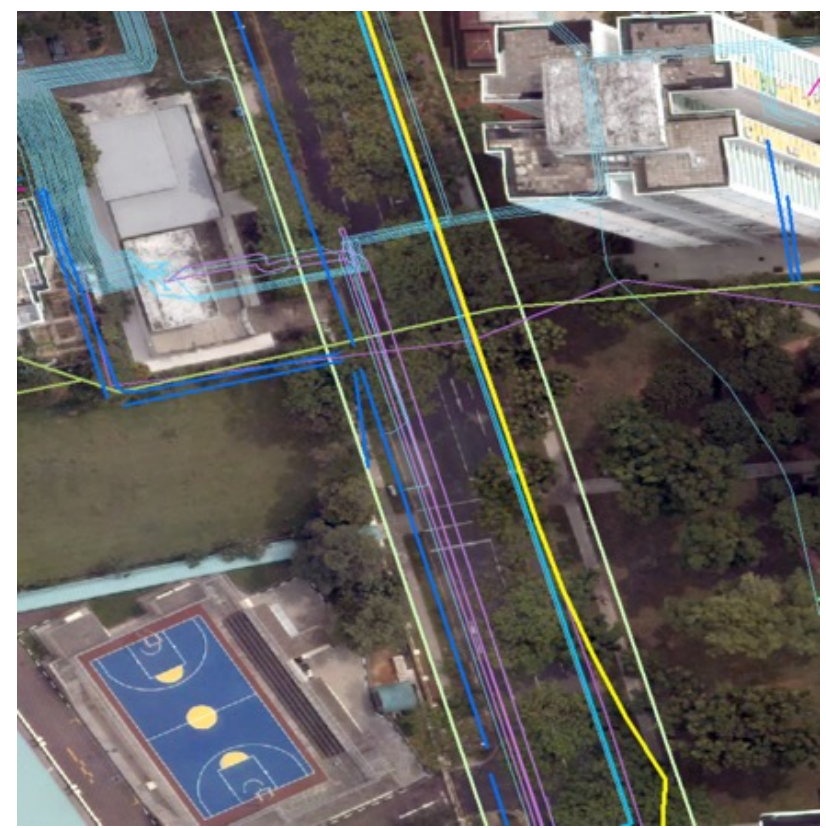

Figure 5. Available map data on existing utilities in highlighted area, Ang Mo Kio.

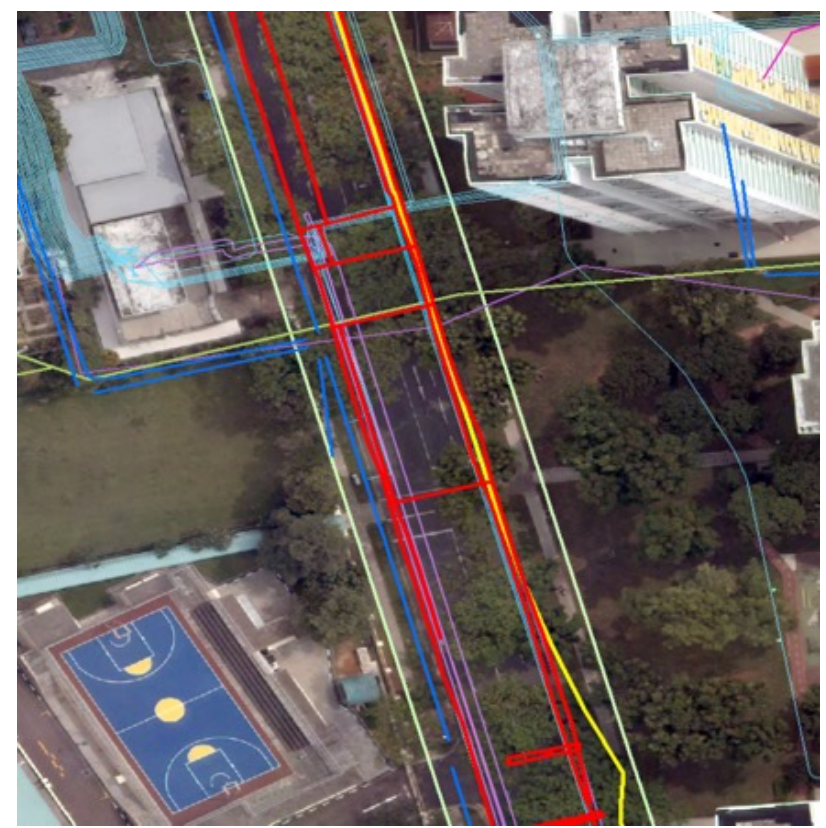

Figure 6. Extracted utilities (red lines) in highlighted area, Ang Mo Kio.

At the northern part of the road, seven utilities are running parallel to the road as indicated by available map data. However, only four utilities can be detected by the GPR. Reasons for not being able to detect all utilities are most likely the fact that they are buried very near to one another, making it challenging for the 
analyst to detect and extract those utilities, as well as the grouping of various cables that are indicated as individual features on the map into single ducts.

At the southern part of the same road, several low voltage cables and two pipes run across the road as indicated by GeoSpace data. Four utilities were detected by the GPR. From the comparison, it is likely that two unmapped or unknown utilities have been found in addition to the ones recorded in the available map data.

\subsection{Marina Boulevard}

The main scanning route in Marina Boulevard is a rectangular, clockwise loop with a length of about $1.2 \mathrm{~km}$. The scanning started and ended at the unloading site. Two of the main roads in this loop consist of five lanes, while the other two roads consist of two lanes. The scanning at Marina Boulevard proved to be fairly straightforward due to an unanticipated nearby car-free Sunday event resulting in a decrease in traffic intensity at the location. Due to the five-lane width of the main roads a large number of scanning passes (nine) had to be conducted. Scanning had to be halted several times due to bad weather conditions during the scanning.

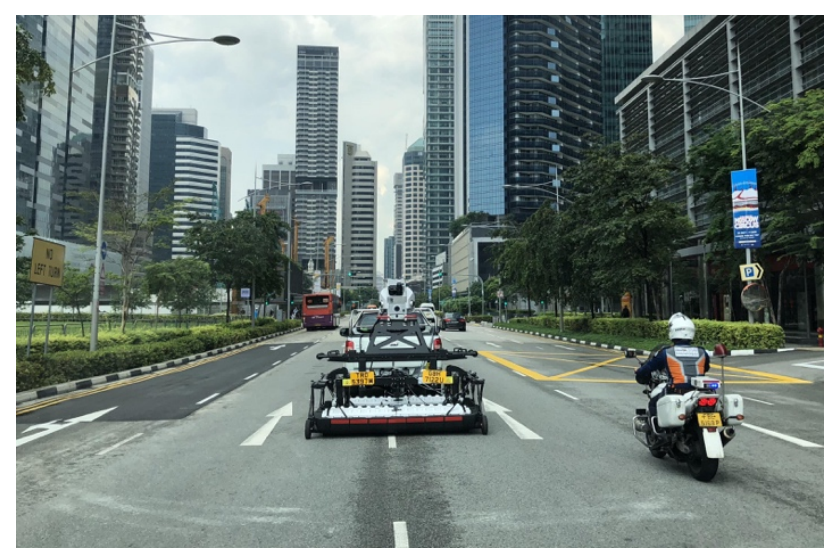

Figure 7. Scanning in between two lanes on a five-lane road, Marina Boulevard.

For detailed evaluation, an excerpt of the area is assessed in greater detail. Figure 8 displays the available map data and the extracted utilities. According to the map data, there are one cable duct and one low voltage cable crossing the road. Three utilities were detected by the GPR. As highlighted in the figure, only one detected utility matches the map data. Other utilities were newly found in the GPR data. The low voltage cable was installed under a rigid pavement, where a concrete slab and the steel in the form of bars or mesh (so-called rebar) were used as a reinforcement. This limited the penetration of the radar signal (Figure 9). From available map data, it appears that most of the utilities are installed under the side table of the road. To cover these areas, a trolley-based system is required.

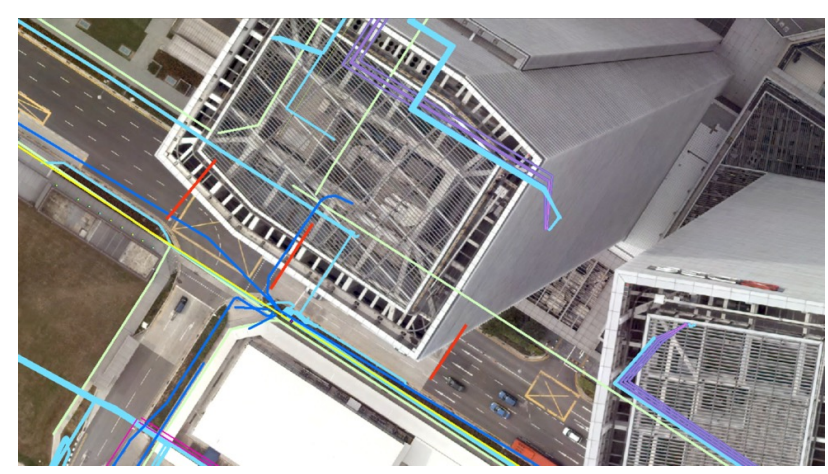

Figure 8. Available map data (non-red lines) and extracted utilities (red lines) in highlighted area, Marina Boulevard.

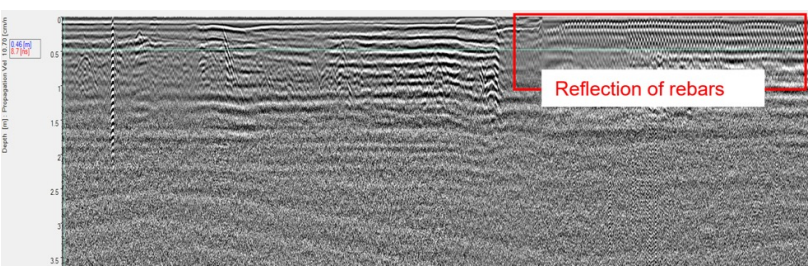

Figure 9. Concrete slab and rebar mesh affecting data quality and interpretation in Marina Boulevard.

\section{CONCLUSIONS}

Over the course of six days, various datasets were captured for large areas in Singapore using a mobile 3D ground penetrating radar platform. Three of those datasets were processed further to extract subsurface utilities and compare the results with available map data.

\subsection{Quality of available map data}

Although no verification of captured data or available map data has been conducted, the results lead to various conclusions regarding the quality of existing available map data. The lack of exact matches between captured and available data underline the need to improve the reliability of subsurface utility map data in Singapore.

Although it is not possible to determine the exact cause of these mismatches, a lack of accuracy and an undefined measure of (in)accuracy of data are observed in available data. Some of these are likely to be caused by proprietary data representation, e.g. representing various cables contained in a single duct as individual features on a map for cartographic purposes. Various subsurface utilities were detected that did not appear to have a match in available data. For older areas of Singapore, these could indicate the presence of old, "legacy" utilities, underlining the need for a complete map. For newer areas, these detected utilities may instead be relatively new, underlining the need for a more current, up to date map of subsurface utilities.

\subsection{Data capture}

Data was captured for each area in less than half a working day. Despite the relatively low travel speed $(15 \mathrm{~km} / \mathrm{h})$, the platform operated in regular traffic conditions without any notable issues. With 3D GPR data capture speeds expected to increase in the near future (Impulse Radar, 2018), the towing vehicle will be able to participate in traffic normally, removing the need for special safety measures. Although data capture was conducted in daylight conditions to capture above ground photo imagery along 
with subsurface radar data, subsurface data capture alone can be conducted at any time of the day or night and allow for capture in relatively easy conditions and circumstances.

\subsection{Data processing}

Although large volumes of data can be captured for large areas in a relatively short amount of time (1.875 person-hours per lane$\mathrm{km}$, based on the Toa Payoh site), data processing is a significantly more laborious and time-consuming effort $(20$ person-hours per lane-km, based on Toa Payoh). The detection, location, and extraction of subsurface utilities from ground penetrating radar data is, at the moment of conducting the case studies, still a mostly manual effort that depends highly on expert interpretation.

From the captured data, it was observed that a penetration depth of up to $2 \mathrm{~m}$ can be achieved in Singapore. It is understood that, in Singapore, some subsurface utilities are installed deeper than that and therefore may be undetectable with ground penetrating radar technology. Another factor that affects the coverage and completeness of processed results for an area is the possibility that utilities that are sufficiently close to one another can't always be detected and extracted as separate assets. And last, the area that can be covered by ground penetrating radar is limited by the accessibility of the surface above. To achieve a full coverage for a road, data for side table areas need to be captured with another, dedicated GPR platform.

A few data quality issues were observed that limited processing of the data, such as the presence of reinforced concrete slabs under certain parts of the road and an occurrence of an area with non-compact soil due to recent excavation works.

\subsection{Feasibility of a nation-wide mapping project}

The study shows that $3 \mathrm{D}$ ground penetrating radar technology combined with a suitable mobile platform can be used to map underground utilities within the first decimetres to meters below the surface at an unprecedented scale, speed and resolution. However, the economic feasibility of mapping underground utilities in large areas using this technology is still limited. There are limits due to the performance and capabilities of currently available processing tools: while the data can be captured in a relatively short amount of time, processing the data still requires a proportionally large amount of manual interaction and expertise, thus taking significantly more time while not guaranteeing identification and location of all utilities assumed to be present. After detection, it is expected that only a subset of the detected utilities can be classified correctly due to a lack of overlap with inaccurate existing maps, thus necessitating further data capture and verification on-site. Additionally, a mapping project covering an entire area would need to at least include not just road surfaces, but also the road side tables. This would involve the use of manually operated, trolley-based platforms that offer a significantly lower data capture speed then the evaluated mobile platform.

\section{DISCUSSION}

Based on the current state of technology and the estimated cost, it is not recommended to take the technology off the shelf and start a nation-wide mapping approach. Although the use of GPR for utility mapping purposes is a visibly growing application area, the use of mobile GPR platforms for large-scale utility mapping is still in its infancy, with many developments ongoing and potential areas for improvement. In particular, while data capture is rapid, data processing isn't. Therefore, it is recommended to investigate the possibilities for increasing the economic viability of large-scale mapping through automation of the processing workflow.

Besides the technology itself, a key point for further development is the availability of skilled practitioners. It is observed that this expertise is currently non-existent in Singapore and needs to be developed from the ground up. Over time, skills and the application of good practices need to be cultivated.

\subsection{Towards an opportunity-driven, gradual improvement of map quality}

Instead of a single mapping project to improve the reliability of a city's map of subsurface utilities at once, it is recommended to adopt a more gradual, opportunity-driven approach. A clear business case already exists for using non-destructive techniques in the planning and design phase of underground-related projects (and in particular large, capital projects). Therefore, it is recommended to include GPR as an accepted data capture technique for initial detection of subsurface utilities, before possibly digging trial trenches for verification and to complement existing map data. Not only does the newly captured data offer direct value to the development project. It can also be used to improve the accuracy of map data for the affected area.

While GPR has already proven to be a feasible complementary technique for locating and mapping utilities prior to large underground infrastructure projects and can therefore be used for information quality improvement in these specific areas, it is not yet an economically viable solution to support general quality reconciliation projects for areas with no urgent need for accurate information. Therefore, it is recommended that additional quality improvement programmes are developed that capitalize on data capture opportunities that occur throughout a utility asset's lifecycle. Beyond utility installation, the following life cycle events can be identified for subsurface utilities: (i) trial trench, (ii) diversion, (iii) repair, (iv) rehabilitation, and (v) replacement (where it should be noted that replacement can be considered a specific form of rehabilitation). All these events offer specific surveying opportunities for which suitable techniques can be identified. The overview presented in Table 2 represents an initial suggestion and requires further investigation and development. Additionally, it may drive the need for further research and development on the application of certain techniques for utility mapping. 


\begin{tabular}{|c|c|c|}
\hline Event & Opportunity & $\begin{array}{l}\text { Recommended } \\
\text { technique(s) }\end{array}$ \\
\hline $\begin{array}{l}\text { Utility } \\
\text { installation }\end{array}$ & $\begin{array}{l}\text { Line of sight; short } \\
\text { window of } \\
\text { opportunity } \\
\text { depending on } \\
\text { situation }\end{array}$ & $\begin{array}{l}\text { Conventional } \\
\text { surveying; laser } \\
\text { scanning }\end{array}$ \\
\hline Trial trench & $\begin{array}{l}\text { Line of sight; short } \\
\text { window of } \\
\text { opportunity }\end{array}$ & Laser scanning \\
\hline Diversion & Line of sight & $\begin{array}{l}\text { Conventional } \\
\text { surveying; laser } \\
\text { scanning }\end{array}$ \\
\hline Repair & $\begin{array}{l}\text { Line of sight for a } \\
\text { small portion of the } \\
\text { utility; very short } \\
\text { window of } \\
\text { opportunity }\end{array}$ & Laser scanning \\
\hline $\begin{array}{l}\text { Rehabilitation } \\
\text { (open trench) }\end{array}$ & Line of sight & $\begin{array}{l}\text { Conventional } \\
\text { surveying; laser } \\
\text { scanning }\end{array}$ \\
\hline $\begin{array}{l}\text { Rehabilitation } \\
\text { (trenchless) }\end{array}$ & $\begin{array}{l}\text { Accessibility from } \\
\text { the inside }\end{array}$ & $\begin{array}{l}\text { Gyroscopic } \\
\text { mapping for } \\
\text { pipes that meet } \\
\text { its criteria }\end{array}$ \\
\hline Replacement & $\begin{array}{l}\text { Line of sight (in the } \\
\text { case of open trench) } \\
\text { or accessibility from } \\
\text { the inside (in the case } \\
\text { of abandonment of } \\
\text { the old pipe) }\end{array}$ & $\begin{array}{l}\text { Conventional } \\
\text { surveying; laser } \\
\text { scanning; } \\
\text { photogrammetry; } \\
\text { gyroscopic } \\
\text { mapping }\end{array}$ \\
\hline
\end{tabular}

Table 2 . Utility life cycle events and potential data capture opportunities and techniques.

\section{ACKNOWLEDGEMENTS}

This publication has been realized as part of the Digital Underground: 3D Mapping of Utility Networks project at the Future Cities Laboratory, established by ETH-Zurich and the Singapore National Research Foundation (NRF), and operating under the auspices of the Singapore-ETH Centre. The project is funded by the UNDERGROUND-RELATED STUDIES AND PROJECTS FUND (USPF) of the Ministry of National Development of Singapore and is sponsored by Singapore Land Authority.

\section{REFERENCES}

Agentschap Telecom, 2018. Feiten en Cijfers over Schade door Graafwerkzaamheden. Agentschap Telecom https://www.agentschaptelecom.nl/documenten/publicaties/201 9/04/10/feiten-en-cijfers-over-schade-doorgraafwerkzaamheden-2018 (15 July 2019).

Energy Market Authority, 2019. Earthworks Contractors. Energy Market Authority https://www.ema.gov.sg/Earthworks_Contractors.aspx (8 May 2019).

Impulse Radar, 2018. Raptor: High Speed Separable Shielded GPR Antenna Solution. Impulse Radar http://www.impulseradar.se/products/raptor/ (15 July 2019).
Lai, W. W.-L., Drobert, X. and Annan, P., 2018. A review of ground penetrating radar application in civil engineering: a 30year journey from locating and testing to imaging and diagnosis. NDT \& E International 96, pp. 58-78.

Makana, Lewis \& Metje, Nicole \& Jefferson, Ian \& Rogers, Chris. (2016). What Do Utility Strikes Really Cost? 10.13140/RG.2.2.14386.50883.

Novo, A., Manacorda, G., and Simi, A., 2013. Multichannel 3D GPR array systems: Recent results in engineering and archaeology. 26th Symposium on the Application of Geophysics to Engineering and Environmental Problems 2013, pp. 433441 .

Osman, H., El-Diraby, T., E., (2005), "Subsurface Utility Engineering in Ontario: Challenges \& Opportunities", Centre for Information Systems in Infrastructure \& Construction (I2C), Department of Civil Engineering, University of Toronto, 2015.

Singapore Land Authority, 2017. Standard and Specifications for Utility Survey in Singapore. Singapore Land Authority https://www.sla.gov.sg/Press-Room/Circulars/Land-Survey (15 July 2019).

Tham, I., 2019. Going Underground - Singapore's New Frontier, The Straits Times, Singapore, 2 May 2019.

Urban Redevelopment Authority, 2019. Draft Master Plan 2019. Urban Redevelopment Authority https://www.ura.gov.sg/Corporate/Planning/Draft-Master-Plan19 (15 July 2019).

Van Son, R., Jaw, S.W., Yan, J., Khoo, V., Loo, R.S., Teo, S., $\&$ Schrotter, G. (2018). A framework for reliable threedimensional underground utility mapping for urban planning. ISPRS Int. Arch. Photogramm. Remote Sens. Spatial Inf. Sci., XLII-4/W10, 209-214.

Zembillas, N., M., and Scott, P., C., (2010), The Evolution of Subsurface Utility Engineering: From concept to Industry Standard, North American Society for Trenchless Technology (NASTT), No Dig Show 2010, Chicago, Illinois, May 2, 2010. 